\title{
Der Markt als Instrument hoheitlicher Verteilungslenkung
}

Möglichkeiten und Grenzen einer marktgesteuerten staatlichen Verwaltung des Mangels

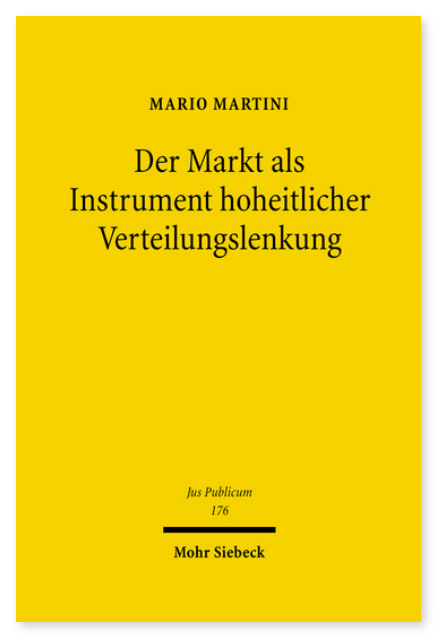

2008. XX, 912 Seiten. JusPubl 176

ISBN 978-3-16-151257-5

DOI 10.1628/978-3-16-151257-5

eBook PDF $204,00 €$

ISBN 978-3-16-149332-4

Leinen $204,00 €$
In einer Zeit, in der die Schere zwischen den Bedürfnissen und den vorhandenen Ressourcen immer weiter auseinander zu klaffen droht, wird der Ruf nach knappheitsgerechten Verteilungsmechanismen immer lauter. Namentlich die Ökonomik reklamiert für sich den Anspruch, einen sinnvollen Beitrag zur Optimierung der staatlichen Verteilungsordnung erbringen zu können. Mario Martini geht den komplexen Fragen grundrechtlicher wie finanzverfassungsrechtlicher Natur nach, die eine Implementierung des Marktes als Instrument staatlicher Verwaltung des Mangels aufwirft. Ihre Bandbreite reicht von der Gemeinwohlorientierung des Zuteilungsmechanismus, der Steuerungsverantwortung des Parlaments über die Gefahren staatlicher Pleonexie, der Vereinbarkeit mit dem Gedanken des Steuerstaates sowie dem finanzverfassungsrechtlichen Äquivalenzprinzip bis hin zu Fragen der Gleichheit in der Zeit und der Risikozuordnung zwischen Staat und

Grundrechtsträgern. Ausgehend von dem Gedanken, dass die Wahl des Marktes als Handlungsinstrument den Staat nicht der Verantwortung für die Verteilungsergebnisse enthebt, rekonstruiert der Autor die Grundrechte als verfassungsrechtliche Grenze der Risikozuweisung. Die Ergebnisse werden auf die wichtigsten denkbaren Referenzbereiche marktwirtschaftlicher Primär- und Sekundärallokation heruntergebrochen, insbesondere Frequenzen, Umweltnutzungsrechte, Start- und Landerechte, Rohstoffabbaurechte oder Außenwirtschaftsgenehmigungen.

Mario Martini Geboren 1969; Studium der Rechtswissenschaften an der Johannes Gutenberg-Universität Mainz; 1999 Promotion; 2006 Habilitation; wissenschaftlicher Assistent an der Bucerius Law School, Hamburg.

Jetzt bestellen:

https://mohrsiebeck.com/buch/der-markt-als-instrument-hoheitlicher-verteilungslenkung-9783161512575?no_cache=1 order@mohrsiebeck.com

Telefon: +49 (0)7071-923-17

Telefax: +49(0)7071-51104 